\title{
EQUILIBRIUM WAGE-TENURE CONTRACTS
}

\author{
By Ken BuRdeTt AND MELVYN COLES ${ }^{1}$
}

\begin{abstract}
In this study we consider a labor market matching model where firms post wagetenure contracts and workers, both employed and unemployed, search for new job opportunities. Given workers are risk averse, we establish there is a unique equilibrium in the environment considered. Although firms in the market make different offers in equilibrium, all post a wage-tenure contract that implies a worker's wage increases smoothly with tenure at the firm. As firms make different offers, there is job turnover, as employed workers move jobs as the opportunity arises. This implies the increase in a worker's wage can be due to job-to-job movements as well as wage-tenure effects. Further, there is a nondegenerate equilibrium distribution of initial wage offers that is differentiable on its support except for a mass point at the lowest initial wage. We also show that relevant characteristics of the equilibrium can be written as explicit functions of preferences and the other market parameters.
\end{abstract}

KEYWORDS: Search, contracts, turnover, wage-tenure, wage dispersion.

\section{INTRODUCTION}

THE OBJECTIVE OF THIS STUDY is to analyze equilibrium in a labor market where firms post wage/tenure contracts and workers-both employed and unemployed-search for better paid job opportunities. Given the environment faced, we show that in equilibrium the contract offered by any firm implies the worker's wage increases with tenure at that firm. Further, although firms in equilibrium do not offer the same contract, they are all related to a single wage/tenure contract with different firms offering different starting points on that contract. This implies that employed workers change jobs over time, and do so whenever they contact a firm offering better wages than those currently earned. Hence, a worker's wage increases over time due to both wage/tenure effects and to quitting to better paid employment. As we can explicitly solve for the major characteristics of the model in equilibrium, the results lead to several predictions about the labor market histories of workers and the nature of labor market equilibria that have not been exploited to date.

During the last ten years or so a literature has developed based on the equilibrium analysis of labor markets where employed workers continue search for better job opportunities. Much of this work has been based on the framework developed by Burdett and Mortensen $(1989,1998)$ (hereafter termed B/M). ${ }^{2}$ A critical feature of the $\mathrm{B} / \mathrm{M}$ framework is that each firm posts a single pricea wage that it pays all of its employees at each point in time. In the context of a

\footnotetext{
${ }^{1}$ We would like to acknowledge the financial support given by the Leverhulme Trust in supporting the project 'Labor Market Dynamics in a Changing Environment.' We would also like to thank two anonymous referees and the Editor for helpful comments. We are, of course, responsible for any errors.

${ }^{2}$ Albrecht and Axell (1984), Eckstein and Wolpin (1990), and Acemoglu and Shimer (1999) provide interesting alternative approaches.
} 
relatively standard matching framework with identical firms and workers, equilibrium with on-the-job search implies a nondegenerate distribution of wage offers. $^{3}$ The logic is relatively simple. Firms offering a high wage make less profit per employee than those firms offering a lower wage. On-the-job search, however, implies those firms offering higher wages attract more workers and so enjoy a larger steady-state labor force. In equilibrium, all firms obtain the same steady-state profit flow, even though they offer different wages.

This framework has proved to be empirically useful as it can be used to explain why observationally equivalent workers earn different wages (see van den Berg (1999) for a recent survey). ${ }^{4}$ An important theoretical shortcoming of the $\mathrm{B} / \mathrm{M}$ framework, however, is that more efficient wage contracts potentially exist. ${ }^{5}$ For example with complete financial markets, Stevens (2002) shows the first best contract specifies a hiring fee that workers pay on being hired. The worker is then paid marginal product while employed, which ensures any subsequent quit decision is jointly efficient.

This paper extends the $\mathrm{B} / \mathrm{M}$ framework to equilibria where firms do not post a single wage, but post contracts where the wage paid depends on an employee's tenure at the firm. Two central restrictions play a large part in establishing our results. First, we assume imperfect capital markets. Being liquidity constrained, workers cannot pay an up-front fee for their job and so firms can only extract rents from employees by paying wages below marginal product. Employees then recover part of those rents through on-the-job search for better paid employment opportunities. Second, we assume that workers are strictly risk averse. These two restrictions imply there are two basic forces at work. As employees obtain job offers from other firms, there is an incentive for firms to backload wages in any wage/tenure profile. By offering a worker a smaller wage today but a greater wage at some future date, a firm reduces its current wage bill and also increases an employee's expected return to staying with the firm. This, in turn, reduces an employee's quit probability. Strictly risk averse employees, however, prefer, ceteris paribus, a constant wage paid per period. An optimal contract trades off these two competing effects. As we shall see, it leads to an optimal contract where wages increase smoothly with tenure.

In related work, Stevens $(1999,2002)$ establishes that when workers are risk neutral and there are no financial markets, a step wage/tenure contract is optimal-a firm pays a zero wage for short tenures, and pays marginal product once the worker's tenure exceeds some threshold. She also establishes that equilibrium is always degenerate, where all firms offer the same step contract

${ }^{3} \mathrm{As} \mathrm{B} / \mathrm{M}$ show, it is also straightforward to generalize this framework to consider heterogeneous firms without disturbing the basic results.

${ }^{4}$ Bontemps, Robin, and van den Berg (1999, 2000), Postel-Vinay and Robin (2002b), and van den Berg and Ridder (1998) provide even more recent contributions to the empirical literature. A recent insightful review of the theoretical literature is provided by Mortensen (2002).

${ }^{5}$ Shimer (1996) was perhaps the first to make this point. 
and there is no quit turnover. Furthermore in this degenerate equilibrium, there is a continuum of alternative contracts that are payoff equivalent to the equilibrium step contracts.

Our paper finds that when workers are strictly risk averse, the distribution of contract offers is necessarily nondegenerate. When we consider the special case where workers have a constant relative risk averse utility function, then as risk aversion goes to zero, we find that the limiting equilibrium implies all firms offer the same wage/tenure contract and there is no quit turnover. The limiting wage tenure contract, however, is unique and is a smooth, strictly increasing function of tenure. Even so, it is payoff equivalent to those characterized by Stevens, which are in turn payoff equivalent to the Diamond paradox (Diamond (1971)). In this limiting case, a degenerate contract offer distribution implies workers obtain no surplus through search.

In contrast, we also show that as the coefficient of risk aversion becomes infinite, the market equilibrium converges to the B/M equilibrium. Infinitely risk averse workers imply a flat wage/tenure contract is optimal. As in $\mathrm{B} / \mathrm{M}$, all individual worker wage growth arises through quitting to better paid employment, and greater wage competition by firms for employed workers leads to wages paid being more generous than in the pure monopsony case.

An important element of our results is that the equilibrium is characterized by a baseline salary scale. The baseline salary scale is the equilibrium wage/tenure profile of a firm offering the lowest starting wage for new hires in the market. It is shown that any other firm's wage tenure profile can be described by this baseline salary scale with a different starting point. For example, suppose a firm offers a starting wage that is the same as the baseline salary at (say) 7 months tenure. An optimal contract implies employees at this firm are paid a wage after 3 months equal to the wage paid at 10 months according to the baseline salary scale. And so on. This, of course, leads to a strong testable restriction on possible wage/tenure profiles offered by firms.

The resulting market equilibrium implies different firms offer different starting points on the underlying baseline salary scale. As in the original $\mathrm{B} / \mathrm{M}$ framework, all firms obtain the same steady state profit, even though they offer different wage contracts. Here, however, wages rise with tenure at a firm. The underlying empirical implications are that within a firm, workers with shorter tenures earn lower wages and are more likely to quit, while across firms, those firms that offer more generous wage-tenure contracts have lower average quit rates and attract more workers.

An important assumption made in the paper is that a firm does not respond to outside offers received by any of its employees. Clearly this restriction is not satisfied in some labor markets such as the academic labor market in the U.S. Nevertheless, there are reasons to suspect our restriction holds in other labor markets, especially those markets where workers are homogenous. First, outside offers may not be observable by firms. Indeed, why should a firm verify to another firm that it has made a particular offer to a worker? Of course, 
given offers from other firms are not observed, they will be ignored. Second, as we assume throughout that all workers are equally productive, some employees may well become disgruntled should a no more talented and more junior employee receive a higher wage on the basis of some random outside offer.

In contrast, suppose firms do respond to outside offers. In an insightful study, Postel-Vinay and Robin (2002a) assume that the two firms- the worker's current employer and the firm that made the outside offer-enter into a Bertrand bidding game. Although Postel-Vinay/Robin consider heterogeneous firms, the homogeneous firm and worker case is insightful. In this case, if any employee of a firm contacts another firm, then both firms make the same bid - the worker's marginal product. The worker then stays at his or her current employer but yields no further profit to it. Unemployed workers are hired at a starting wage below the flow value of being unemployed, where a new hire anticipates a higher future wage through continuing search for an outside offer. We obtain a similar result here though not because workers expect higher wages through generating outside offers, but because wages increase automatically with tenure. This creates a foot-in-the-door effect where unemployed workers will accept a low starting wage as an investment in higher future wages.

In the next section we specify the basic elements of the model. As the derivation of the results is not trivial, things are kept reasonably simple. After briefly describing the optimal quit behavior of workers, we first derive the optimal contract a firm offers within a particular matching environment (Theorem 1). We then construct a market equilibrium and derive closed form solutions for the distribution of starting wages, the distribution of wages paid, and the underlying baseline salary scale (Theorem 2 ). The final section discusses the implications of our results and various extensions.

\section{BASIC FRAMEWORK}

Time is continuous and only steady states are considered. Suppose there is a unit mass of workers and of firms who participate in a labor market. Workers and firms are homogeneous in that any firm generates revenue $p$ for each worker it employs per unit of time. Both unemployed and employed workers obtain new job offers from time to time. Let $\lambda$ denote the Poisson arrival rate of new job offers faced by any worker (employed or unemployed). Any job offer is fully described by the wage contract offered by the firm. Such a contract specifies the wage the worker receives as a function of his or her tenure at that firm, i.e., an offer is a function $w() \geq$.0 defined for all tenures $t \geq 0$. As employees are equally productive, assume a firm offers all new hires the same contract. ${ }^{6}$ Also assume there is no recall should a worker quit or reject a job offer. ${ }^{7}$

${ }^{6}$ For example, anti-discrimination legislation might require equal treatment of all new hires.

${ }^{7}$ The no recall assumption is used for tractability. In equilibrium, a worker would never wish to return to a previously contacted employer who is paying relatively low wages. 
An important simplification is that firms and workers have a zero rate of time preference. The objective of any firm is to maximize steady state flow profit. Workers are strictly risk averse and are finitely lived, where any worker's life is described by an exponential random variable with parameter $\delta>0$. The objective of any worker is to maximize total expected lifetime utility. To maintain a steady state, $\delta$ also describes the inflow of new unemployed workers into the market. Assume unemployed workers obtain $b$ per unit of time and that $p>b>0$.

\subsection{Worker Payoffs and Job Search Strategies}

Each worker takes as given the firm's posted wage contract $w($.$) , which spec-$ ifies the wage it pays any employee at any tenure $t$. There are no financial markets so that a worker who obtains income $w \geq 0$ at any instant of time obtains flow utility $u(w)$ by immediately consuming it. ${ }^{8}$ We now impose the following restriction on this utility function.

A1: Assume $u$ is strictly increasing, strictly concave, and twice differentiable such that $\lim _{w \rightarrow 0^{+}} u(w)=-\infty$.

Although restrictive, A1 much simplifies the analysis by ensuring that the corner constraint $w \geq 0$ is never binding. Later, alternatives to this restriction are discussed in detail.

Given a job offer $w($.$) , a worker calculates his/her expected lifetime utility$ conditional on accepting it and using an optimal quit strategy in the future. Let $V_{0}$ denote this return. Further, let $F\left(V_{0}\right)$ denote the proportion of firms whose contract offer, if accepted, yields an expected lifetime utility no greater than $V_{0}$. As search is random, $F\left(V_{0}\right)$ also describes the probability that any offer received yields an expected lifetime utility no greater than $V_{0}$. Let $\underline{V}(\bar{V})$ denote the infimum (supremum) of the support of $F$.

Suppose a worker with tenure $t$ is employed by a firm offering contract $w($.$) .$ Let $V(t \mid w()$.$) denote this worker's expected lifetime payoff when using an$ optimal quit strategy in the future. Similarly, let $V_{u}$ denote an unemployed worker's expected lifetime payoff.

Given any contract $w($.$) and any tenure t$ where $V(t \mid w())>.V_{u}$, the no recall assumption implies the worker will quit if and only if he/she receives a job offer that has starting value $V_{0}>V(t \mid w()$.$) . Standard arguments imply V($.) satisfies

$$
\begin{aligned}
& \delta V(t \mid w(.))-\frac{d V(t \mid w(.))}{d t} \\
& =u(w(t))+\lambda \int_{V(t \mid w(.))}^{\bar{V}}\left[V_{0}-V(t \mid w(.))\right] d F\left(V_{0}\right) .
\end{aligned}
$$

\footnotetext{
${ }^{8}$ As equilibrium implies that each worker's wage is strictly increasing over time, an employed worker has no incentive to save for future consumption.
} 
If $V(t \mid w())<.V_{u}$ for some tenure $t$, the worker's optimal strategy is to quit into unemployment. Although this event never occurs in equilibrium, at this stage we need to allow for this possibility and so define $T=\inf \{t \geq 0$ : $\left.V(t \mid w())<.V_{u}\right\}$. Hence, $T$ denotes the tenure at which a worker optimally quits into unemployment. If $V(t \mid w().) \geq V_{u}$ for all $t$, then define $T=\infty$.

Optimal job search therefore implies the following worker strategies:

(i) if unemployed, the worker accepts a job offer if it has starting value $V_{0} \geq V_{u}$;

(ii) if employed with contract $w($.) and tenure $t<T$, the worker quits if and only if a job offer is received with starting value $V_{0}>V(t \mid w()$.$) ;$

(iii) if employed with contract $w($.$) and tenure t=T<\infty$, the worker quits into unemployment.

Given wage contract $w($.$) and tenure s<T$, a worker leaves a firm's employment at rate $\delta+\lambda(1-F(V(s \mid w()))$.$) . For tenures t<T$, the survival probability

$$
\psi(t \mid w(.))=e^{-\int_{0}^{t}[\delta+\lambda(1-F(V(s \mid w(.))))] d s}
$$

describes the probability a newly employed worker does not leave the firm before tenure $t$. Of course if $T<\infty$, then $\psi=0$ for all $t \geq T$.

\subsection{Firm Payoffs}

Let $G(V)$ denote the steady state number of workers who are either unemployed or employed currently enjoying an expected lifetime utility less than $V$. Now consider a firm that posts contract $w($.$) and let V_{0}$ denote a worker's expected lifetime payoff by accepting this contract. If $V_{0}<V_{u}$ the firm attracts no workers and so obtains zero profit. Suppose instead $V_{0} \geq V_{u}$. The definition of $G$ implies $G\left(V_{0}\right)$ describes the number of workers who are willing to accept the firm's job offer; it includes those who are unemployed with payoff $V_{u} \leq V_{0}$ and those employed with payoff $V<V_{0}$. Hence, $\lambda G\left(V_{0}\right)$ describes this firm's hiring rate and its steady state flow profit is given by

$$
\Omega=\int_{0}^{\infty} \lambda G\left(V_{0}\right) \psi(t \mid w(.))[p-w(t)] d t .
$$

Note, $\lambda G\left(V_{0}\right) \psi(t \mid w()) d$.$t describes the number of employees with tenures$ $[t, t+d t)$, and $[p-w(t)]$ is the profit flow generated by each of those workers. This expression can be rearranged as

$$
\Omega=\left[\lambda G\left(V_{0}\right)\right]\left[\int_{0}^{\infty} \psi(t \mid w(.))[p-w(t)] d t\right],
$$

and note that the firm's steady state flow profit equals its hiring rate $\lambda G\left(V_{0}\right)$ times its expected profit per new hire. 
In what follows, we decompose the firm's optimization problem into two components. First, conditional on offering a new hire lifetime payoff $V_{0} \geq V_{u}$, we define an optimal contract $w($.$) as one that maximizes the firm's expected$ profit assuming the worker accepts the offer; i.e., conditional on $V_{0}$, an optimal wage contract solves the programming problem

$$
\max _{w(.) \geq 0} \int_{0}^{\infty} \psi(t \mid w(.))[p-w(t)] d t
$$

subject to $V(0 \mid w())=.V_{0}$, where $\psi(t \mid w()$.$) is determined by the worker's opti-$ mal job search strategy described earlier. This optimal contracting problem is considered in Section 3 below.

Assuming an optimum exists, let $w^{*}\left(. \mid V_{0}\right)$ denote the optimal wage tenure contract and let $\Pi^{*}\left(0 \mid V_{0}\right)$ denote the firm's maximized payoff per new hire. Optimized steady state flow profits then reduce to $\Omega^{*}\left(V_{0}\right)=\lambda G\left(V_{0}\right) \Pi^{*}\left(0 \mid V_{0}\right)$.

\subsection{Definition of Equilibrium}

To simplify the exposition, we impose the following restriction.

A2: For all $V_{0} \in(\underline{V}, \bar{V}), F$ is continuously differentiable and satisfies $F^{\prime}\left(V_{0}\right)>0$.

This restriction is difficult to justify at this stage. We discuss how it may be relaxed later. Notice it requires that the support of $F$ is connected and contains no mass points in its interior. We now define a market equilibrium.

DEFINITION: A market equilibrium is:

(ME1) a distribution of starting payoffs $F$ satisfying A2;

(ME2) a set of optimal wage tenure contracts $w^{*}\left(. \mid V_{0}\right)$ indexed by $V_{0} \geq V_{u}$;

(ME3) optimal job search by unemployed workers, where optimality implies $V_{u}$ satisfies

$$
\delta V_{u}=u(b)+\lambda \int_{V_{u}}^{\bar{V}}\left[x-V_{u}\right] d F(x) ;
$$

(ME4) optimal quit behavior by employees, where $V\left(t \mid w^{*}\right)$ describe the worker's expected lifetime payoff at tenure $t$ given wage contract $w^{*}($.$) ;$

(ME5) a distribution of expected lifetime payoffs $G$ consistent with steady state turnover; and

(ME6) a steady state profit condition

$$
\begin{aligned}
& \Omega^{*}\left(V_{0}\right)=\bar{\Omega} \geq 0 \text { for all } V_{0} \in[\underline{V}, \bar{V}], \\
& \Omega^{*}\left(V_{0}\right) \leq \bar{\Omega}, \quad \text { otherwise, }
\end{aligned}
$$


so that any offered contract (i.e., an optimal contract $w^{*}$ with starting value $V_{0}$, which lies in the support of $F$ ), maximizes steady state flow profit.

The following fully characterizes a market equilibrium given preferences satisfy A1 and shows that one always exists. The next section characterizes $w^{*}$, the set of optimal wage contracts. Given those results, the equilibrium structure then becomes transparent and Section 4 will fully characterize the equilibrium (and prove existence). Section 5 then discusses the results.

\section{OPTIMAL WAGE-TENURE CONTRACTS}

The objective in this section is to derive the contract that maximizes a firm's expected profit per new employee, given it yields an expected lifetime utility of $V_{0}$ to a worker who accepts it and uses an optimal quit strategy. Such a contract is termed an optimal contract. As previously stated, there are two forces that determine the nature of this contract. First, as capital markets are imperfect, there is an insurance problem where, ceteris paribus, risk averse workers prefer a constant wage stream. Second, there is a moral hazard problem where an employee quits if a better outside offer is received.

When designing an optimal contract, each firm takes as given (a) $F$, the distribution of contracts offered by other firms in the market, (b) $V_{u}$, the expected lifetime utility of an unemployed worker, and (c) the optimal quit strategy of an employed worker given the contract offered. The firm's formal optimal contracting problem is defined as

$$
\max _{w(.)} \int_{0}^{\infty} \psi(t \mid w(.))[p-w(t)] d t
$$

subject to

$$
\begin{aligned}
& w(.) \geq 0, \\
& V(0 \mid w(.))=V_{0},
\end{aligned}
$$

and $\psi$ is defined by (2) consistent with the worker's optimal quit strategy.

We begin by making some preliminary points. First, note the arrival rate of further job offers, $\lambda$, is independent of a worker's employment status, and so any unemployed worker accepts a contract that offers $w(t)=b$ for all $t$. As $b<p$ by assumption, a firm can always obtain strictly positive profit by offering this contract. Equilibrium therefore implies (a) firms make strictly positive profit, $\bar{\Omega}>0$; (b) $\underline{V} \geq V_{u}$ (as a firm that offers $V_{0}<V_{u}$ makes zero profit); and (c) $\bar{V}<u(p) / \delta$ (no firm pays a worker more than the worker's expected value). Hence, in the above optimization problem, we assume that $F$ not only satisfies A2, but also $V_{u} \leq \underline{V}$ and $\bar{V}<u(p) / \delta$. 
Optimality also implies $T\left(w^{*}\right)=\infty$-an employed worker never quits into unemployment. In particular if $T<\infty$ existed, the firm could strictly increase profit by instead setting $w(t)=b$ for all $t \geq T$. In that case, the worker obtains the same payoff $V(t \mid w(t)=b)=V_{u}$ at all $t \geq T$, and therefore the worker does not quit to unemployment and $b<p$ implies the firm makes strictly greater profit with this alternative contract.

Claim 1 describes the optimal wage contract of a firm that offers $V_{0} \geq \bar{V}$.

Claim 1: Fix an $F$ satisfying $A 2$ and $a V_{u} \leq \underline{V}$. If $V_{0} \geq \bar{V}$, the optimal wage contract implies $w(t)=w_{0}$ for all $t$ where $u\left(w_{0}\right)=\delta V_{0}$, and an employee never quits to another firm.

PROOF: Fix $V_{0} \geq \bar{V}$. Now consider the wage contract $w()=.w_{0}$ where $w_{0}$ is defined in the Claim. The Bellman equation (1) implies $V(t \mid w())=.V_{0}$ for all $t$, where $V_{0} \geq \bar{V} \geq V_{u}$ implies the worker never quits. As this contract is jointly efficient (it offers full insurance and the worker never quits) and also extracts maximal employee rents (given $V_{0}$ ), it maximizes the firm's profit. Q.E.D.

As it plays a most important role in what follows, for a given $F$ we define $\bar{w}$ by $u(\bar{w})=\delta \bar{V}$. Claim 1 establishes that a firm that offers the contract that yields the greatest lifetime utility to new hires (i.e., sets $V_{0}=\bar{V}$ ), provides perfect income insurance-it offers a constant wage $w(t)=\bar{w}$ for all $t$. As an employee never quits at such a firm, the firm's expected profit $\bar{\Pi}$ per hire is $\bar{\Pi}=$ $[p-\bar{w}] / \delta$, and note that strictly positive profit requires $\bar{w}<p$.

We now turn to a firm that offers a contract that yields $V_{0}$, where $\underline{V} \leq V_{0}$ $<\bar{V}$. Such a firm faces a positive risk that its employees quit to competing firms. What follows establishes that in the optimal contract, a firm will gradually increase wage payments with tenure.

Let $w^{*}\left(. \mid V_{0}\right)$ denote a firm's optimal contract, given $V_{0}$. Further, let $V^{*}\left(\tau \mid V_{0}\right)$ denote an employee's expected lifetime utility when employed with tenure $\tau$ at a firm that offers contract $w^{*}$ and let $\Pi^{*}\left(\tau \mid V_{0}\right)$ denote the firm's expected profit given this employee. ${ }^{9}$

THEOREM 1: Fix an $F$ satisfying $A 2$ and assume $V_{u} \leq \underline{V}$. For any $V_{0} \in[\underline{V}, \bar{V})$, the optimal contract $w^{*}$ and corresponding worker and firm payoffs $\left\{V^{*}, \Pi^{*}\right\}$ are solutions to the differential equation system $\{w, V, \Pi\}$ :

$$
\begin{aligned}
& \frac{-u^{\prime \prime}(w)}{u^{\prime}(w)^{2}} \frac{d w}{d t}=\lambda F^{\prime}(V) \Pi, \\
& \delta V-\frac{d V}{d t}=u(w)+\lambda \int_{V}^{\bar{V}}[x-V] F^{\prime}(x) d x,
\end{aligned}
$$

${ }^{9}$ Note, $V^{*}\left(. \mid V_{0}\right)$ is equivalent to $V\left(. \mid w^{*}\right)$. 


$$
[\delta+\lambda(1-F(V))] \Pi-\frac{d \Pi}{d t}=[p-w],
$$

subject to the boundary conditions:

(a) $\lim _{t \rightarrow \infty}\{w(t), V(t), \Pi(t)\}=(\bar{w}, \bar{V}, \bar{\Pi})$, and

(b) the initial condition $V(0)=V_{0}$.

PROOF: See Appendix.

Equations (8) and (9) are standard flow equations describing the continuation payoffs $V^{*}$ and $\Pi^{*}$. For example, (8) is implied by the worker's Bellman equation (1), while integration of (9) and boundary condition (a) (which implies boundedness) gives

$$
\Pi^{*}(t \mid .)=\int_{t}^{\infty} \frac{\psi\left(\tau \mid w^{*}\right)}{\psi\left(t \mid w^{*}\right)}\left[p-w^{*}(\tau \mid .)\right] d \tau,
$$

which is the firm's expected future profit given an employee with current tenure $t$.

The central economic insight is provided by (7), which describes how wages change optimally with tenure. As $\Pi>0$ and $F^{\prime}>0$ by assumption, (7) implies wages are strictly increasing with tenure while $V \in(\underline{V}, \bar{V})$. Note, given an employee with current expected payoff $V=V^{*}\left(\tau \mid\right.$.), the density function $F^{\prime}(V)$ measures the number of firms whose outside offer will marginally attract this worker. If there are no such firms, i.e., if $F^{\prime}(V)=0$, then marginally raising the worker's wage $w^{*}(\tau \mid$.) at tenure $\tau$ has no marginal effect on the worker's quit rate at $\tau$. Optimal insurance then implies the firm pays a (locally) constant wage (cf. Claim 1 for $V \geq \bar{V}$ ). Given $F^{\prime}(V)>0$, however a slightly higher wage then results in a marginally lower quit rate and (7) then describes the optimal trade-off. More intuitively, integrating (7) over $[0, \tau]$ implies that the optimal wage contract satisfies

$$
\frac{u^{\prime}\left(w^{*}(0 \mid .)\right)}{u^{\prime}\left(w^{*}(\tau \mid .)\right)}=1+u^{\prime}\left(w^{*}(0 \mid .)\right) \int_{0}^{\tau} \lambda F^{\prime}\left(V^{*}(t \mid .)\right) \Pi^{*}(t \mid .) d t .
$$

By marginally increasing the wage paid at tenure $\tau$, the firm reduces marginally the worker's quit rate over $[0, \tau]$. The integral term in (11) measures the firm's overall return to that decreased quit rate, which then distorts the optimal wage contract away from full insurance.

As is standard with moral hazard, the optimal contract rewards those who do not quit - in this case the principal increases payments for those with higher tenure. Being liquidity constrained, new employees are potentially made worse off (as they cannot borrow against future earnings) but the promise of higher earnings in the future lowers their quit rate and increases joint surplus (where a quit is jointly inefficient). 
Given wages increase with tenure, so does the value of employment, $V^{*}(t \mid$.). Further, as wages keep rising while $V^{*}<\bar{V}$, there comes a point where $V^{*}$ equals (or is at least very close to) $\bar{V}$. Claim 1 describes the optimal contract for $V=\bar{V}$, and boundary condition (a) ensures that the limiting contract is optimal. The optimal wage contract is then identified by using backward induction: start at the terminal point $(\bar{w}, \bar{V}, \bar{\Pi})$, iterate the system $\{w, V, \Pi\}$ backwards over time using (7)-(9), then stop when $V=V_{0}$ and define $t=0$ at that point. Assumption A2 and standard backward induction arguments establish that the implied optimal contract $w^{*}\left(\tau \mid V_{0}\right)$ and $V^{*}\left(\tau \mid V_{0}\right)$ are both continuous and increasing with $\tau$, converging to $\bar{w}$ and $\bar{V}$ respectively.

Note, $(\bar{w}, \bar{V}, \bar{\Pi})$ is a stationary point of the differential equation system (7)-(9). If $\lim _{V \rightarrow \bar{V}} F^{\prime}(V)>0$, the conditions of Theorem 1 imply that $w^{*}$ converges to $\bar{w}$ in finite time. Claim 2 in the next section, however, establishes that this cannot occur in a market equilibrium; i.e., a market equilibrium will imply $F^{\prime}(V)$ tends to zero in this limit. In that case the optimal wage contract has the saddle path property.

Given the set of optimal contracts as described in Theorem 1 , we now focus on the contract offered by the least generous firm-the one that offers $V_{0}=\underline{V}$.

DEFINITION: Given an $F$ satisfying A2, the baseline salary scale, denoted $\left\{w_{s}(t), V_{s}(t), \Pi_{s}(t)\right\}$, is the solution to the differential equations and boundary conditions defined in Theorem 1 with $V_{0}=\underline{V}$.

The baseline salary scale is important as it can be used to describe the optimal wage contract of any firm offering a starting payoff $V_{0} \in[\underline{V}, \bar{V})$. In particular, Assumption A2 and the equations of Theorem 1 imply that $w_{s}($.$) and$ $V_{s}($.$) are both continuous and increasing functions that converge to \bar{w}$ and $\bar{V}$ respectively. Hence, given any other starting payoff $V_{0} \in(\underline{V}, \bar{V})$, a salary point $t_{0}>0$ exists where $V_{s}\left(t_{0}\right)=V_{0}$. Further, optimality of $w_{s}$ implies that the optimal wage contract given starting payoff $V_{0}=V_{s}\left(t_{0}\right)$ corresponds to the wage tenure payments $w_{s}($.$) described for tenures t \geq t_{0}$. This yields the convenient result that $w^{*}\left(t \mid V_{0}\right) \equiv w_{s}\left(t+t_{0}\right)$; i.e., given any starting salary point $t_{0} \geq 0$, an optimal wage contract pays a worker with tenure $t$ a wage commensurate with point $\left(t_{0}+t\right)$ on the baseline salary scale. Note, this also implies the firm's continuation payoff $\Pi^{*}\left(t \mid V_{0}\right) \equiv \Pi_{s}\left(t+t_{0}\right)$.

The next section now characterizes a market equilibrium where firms not only choose an optimal wage tenure contract given $V_{0}$, but also choose $V_{0}$ to maximize steady state profit $\Omega^{*}\left(V_{0}\right)$. A market equilibrium requires that the choices of $V_{0}$ and $w^{*}\left(. \mid V_{0}\right)$ are optimal given distributions $F$ and $G$, and that $F$ and $G$ are, in turn, consistent with those choices and the optimal quit strategies of workers. Not surprisingly, it can be shown that offering a higher $V_{0}$ (or equivalently a higher starting point $t_{0}$ ) implies a firm obtains less profit per hire. On-the-job search, however, implies that offering a higher $V_{0}$ attracts 
more employees. As we show below, a market equilibrium implies disperse wage contract offers.

\section{MARKET EQUILIBRIUM}

The next Claim implies that in a market equilibrium, $w_{s}$ only converges to $\bar{w}$ asymptotically.

Claim 2: At a market equilibrium the functions $F$ and $1-G$ do not have mass points at $\bar{V}$.

Proof: Note, $1-G(V)$ describes the steady state number of workers employed whose current lifetime utility is at least $V$. The proof is by contradiction-suppose in equilibrium that $1-G$ has a mass $\mu>0$ at $\bar{V}$. Claim 1 implies that a firm offering starting payoff $\bar{V}$ enjoys profit $\Omega^{*}(\bar{V})=$ $\lambda(1-\mu)[(p-\bar{w}) / \delta]$. Consider instead a firm offering starting payoff $V^{\varepsilon}>\bar{V}$. Claim 1 implies the optimal contract is a constant wage $w=\bar{w}+\varepsilon$ for some $\varepsilon>0$ and $\Omega^{*}\left(V^{\varepsilon}\right)=\lambda[(p-\bar{w}-\varepsilon) / \delta]$. As equilibrium implies $\bar{w}<p$, then $\mu>0$ implies $\Omega^{*}\left(V^{\varepsilon}\right)>\Omega^{*}(\bar{V})$ for $\varepsilon$ small enough, which contradicts the definition of a market equilibrium. As $1-G$ cannot have a mass point at $\bar{V}$, Claim 1 now implies that $F$ cannot have a mass point at $\bar{V}$.

Q.E.D.

Claim 2 establishes that $w_{s}(t)<\bar{w}$ for all $t$ and so the baseline salary scale only converges to $\bar{w}$ asymptotically. As this also implies $V_{s}(t)<\bar{V}$ for all $t<\infty$, Theorem 1 and A2 imply $w_{s}$ and $V_{s}$ are strictly increasing for all $t$ in a market equilibrium. Given a market equilibrium must exhibit a baseline salary scale, then rather than consider firms as offering starting payoffs $V_{0} \in[\underline{V}, \bar{V}]$, it is more convenient to consider firms as offering starting points $t_{0} \in[0, \infty)$ along the endogenously determined baseline salary scale.

Given the definition of the baseline salary scale, define $F_{s}(t)$ as the distribution of starting points offered by firms on the baseline salary scale, and note that $F(V)$ is determined by $F\left(V_{s}(t)\right)=F_{s}(t)$. Differentiating yields $F^{\prime}\left(V_{s}\right) d V_{s} / d t=d F^{s} / d t$, and A2 implies $F_{s}$ is strictly increasing for all $t$; i.e., $F_{s}$ has connected support $[0, \infty)$. Claim 2 also implies $\lim _{t \rightarrow \infty} F_{s}(t)=1$. Similarly, we can define $\left[1-G_{s}(t)\right]$ as the number of currently employed workers with salary point at least as great as $t \geq 0$ on the baseline salary scale, and note that $G\left(V_{s}(t)\right) \equiv G_{s}(t)$. No mass point in $G$ at $\bar{V}$ implies $\lim _{t \rightarrow \infty} G_{s}(t)=1$. Let $\underline{w}=w_{s}(0), \bar{w}=w_{s}(\infty)$ so that $[\underline{w}, \bar{w}]$ denotes the support of wages paid in a market equilibrium.

ClaIm 3: A market equilibrium implies the baseline salary scale $\left\{w_{s}, V_{s}, \Pi_{s}\right\}$ satisfies the differential equations 


$$
\begin{aligned}
& \frac{-u^{\prime \prime}\left(w_{s}\right)}{u^{\prime}\left(w_{s}\right)^{2}} \frac{d w_{s}}{d t}=\lambda \Pi_{s} \frac{d F_{s} / d t}{d V_{s} / d t}, \\
& \delta V_{s}-\frac{d V_{s}}{d t}=u\left(w_{s}\right)+\lambda \int_{t}^{\infty}\left[V_{s}(\tau)-V_{s}(t)\right] d F_{s}(\tau), \\
& \left\{\delta+\lambda\left[1-F_{s}\right]\right\} \Pi_{s}-\frac{d \Pi_{s}}{d t}=\left[p-w_{s}\right],
\end{aligned}
$$

and the boundary conditions

(a) $\lim _{t \rightarrow \infty}\left(w_{s}(t), V_{s}(t), \Pi_{s}(t)\right)=(\bar{w}, \bar{V}, \bar{\Pi})$ where $\bar{V}=u(\bar{w}) / \delta, \bar{\Pi}=$ $[p-\bar{w}] / \delta$

(b) $V_{s}(0)=\underline{V}$.

PROOF: The proof follows from the definition of the baseline salary scale and Theorem 1, using $F\left(V_{s}\right)=F_{s}, F^{\prime}\left(V_{s}\right)=\left[d F_{s} / d t\right] /\left[d V_{s} / d t\right]$.

Next we compute steady state $G_{s}$.

\section{Claim 4: A market equilibrium implies}

$$
G_{s}(0)=\delta /(\lambda+\delta),
$$

$$
\left[\delta+\lambda\left[1-F_{s}\right]\right] G_{s}+\frac{d G_{s}}{d t}=\delta \quad \text { for } t>0 .
$$

PROOF: As $\underline{V} \geq V_{u}$ in equilibrium, each worker accepts the first job offer received. Further, optimality implies a worker never quits to unemployment and so steady state unemployment equals $\delta /(\lambda+\delta)$. The definition of $G_{s}$ now implies $G_{s}(0)=\delta /(\lambda+\delta)$. Pick any point $t>0$ on the baseline salary scale. Optimal quit turnover implies that an employed worker on salary point $t$ quits only if the outside offer is a higher starting point $t_{0}>t$ on the baseline salary scale. Given $1-G_{s}(t)$ describes the number of employed workers with salary point no lower than $t$, then over any arbitrarily small time interval $d t>0$, steady state turnover implies

$$
\begin{aligned}
\delta d t\left(1-G_{s}(t)\right)= & (1-\delta d t)\left[G_{s}(t)-G_{s}(t-d t)\right. \\
& \left.+G_{s}(t-d t) \lambda d t\left(1-F_{s}(t)\right)\right]+o\left(d t^{2}\right) .
\end{aligned}
$$

Letting $d t \rightarrow 0$ and rearranging yields (15).

Q.E.D.

As $F_{s}$ has connected support $[0, \infty)$, the constant profit condition [ME6] requires $\lambda G_{s}(t) \Pi_{s}(t)=\bar{\Omega}$ for all $t \geq 0$, where $\lambda G_{s}(t)$ is the hiring rate of a firm that offers any starting point $t \geq 0$ and $\Pi_{s}(t)$ is the firm's expected profit per new hire at point $t$ on the baseline salary scale. Letting $t \rightarrow \infty$, a market 
equilibrium implies $G_{s} \rightarrow 1$ and $\Pi_{s} \rightarrow \bar{\Pi}=(p-\bar{w}) / \delta$, which yields $\bar{\Omega}=\lambda(p-$ $\bar{w}) / \delta$. The constant profit condition now reduces to

$$
G_{s}(t) \Pi_{s}(t)=[p-\bar{w}] / \delta \text { for all } t \geq 0 .
$$

Proposition 1 establishes that firms offering the least generous wage contract in the market extract all the surplus from unemployed workers, i.e., $V_{s}(0)=V_{u}$. This leads to the following characterization of a market equilibrium.

PROPOSITION 1: Necessary and sufficient conditions for a market equilibrium are:

(a) a vector of functions $\left\{w_{s}, V_{s}, \Pi_{s}, F_{s}, G_{s}\right\}$ satisfying the four differential equations (12)-(15) and the constant profit condition (16), subject to

$$
\lim _{t \rightarrow \infty}\left(w_{s}(t), V_{s}(t), \Pi_{s}(t), G_{s}(t), F_{s}(t)\right)=(\bar{w}, \bar{V}, \bar{\Pi}, 1,1)
$$

where $\bar{w}<p, \bar{V}=u(\bar{w}) / \delta, \bar{\Pi}=[p-\bar{w}] / \delta$;

(b) $G_{s}(0)=\delta /(\lambda+\delta)$;

(c) $V_{u}=V_{s}(0)$ where

$$
\delta V_{u}=u(b)+\lambda \int_{0}^{\infty}\left[V_{s}(t)-V_{u}\right] d F_{s}(t) ;
$$

and $F_{s}, G_{s}$ must have the properties of distribution functions, and imply $F(V)$ has properties $A 2$.

PROOF: We prove these conditions are both necessary and sufficient in turn.

Necessary. Strictly positive profit implies $V_{u} \leq V_{s}(0)$. Suppose for the moment $V_{u}<V_{s}(0) \equiv \underline{V}$. Now consider the conditions of Theorem 1, but with starting payoff $V_{0} \in\left[V_{u}, V_{s}(0)\right)$. The optimal contract implies an early tenure phase for some $\tau>0$, where the firm pays a fixed wage $w_{0} \in(0, \underline{w}]$ for tenures $t<\tau$, and wages $w=w_{s}(t-\tau)$ for tenures $t \geq \tau$. It is straightforward to argue that this contract generates strictly greater profit per hire. ${ }^{10}$ As the hiring rate is the same as for a firm offering $V=\underline{V}$, this implies $\Omega^{*}\left(V_{0}\right)>\Omega^{*}(\underline{V})$, which contradicts the definition of a market equilibrium. Hence, $V_{u}=V_{s}(0)$ is a necessary condition of equilibrium.

Note that the equation for $V_{u}$ given in Proposition 1(c) follows from the definition of $V_{u}$ in a market equilibrium and that $V_{u}=V_{s}(0) \leq V_{s}(t)$ for all $t \geq 0$. Claims 2-4 now imply Proposition 1 describes necessary conditions for a market equilibrium.

Sufficient. By construction of the baseline salary scale, any starting point $t \geq 0$ implies the firm is offering an optimal wage contract, and the constant

\footnotetext{
${ }^{10}$ See (17), and note that $d V / d t>0$ implies $d \Pi / d t<0$.
} 
profit condition (16) guarantees that each optimal contract offered generates the same steady state profit $\bar{\Omega}>0$. Further, any other contract that offers $V<V_{s}(0)$ is rejected by workers and so generates zero profit, whereas any optimal contract that offers $V>V_{s}(\infty)=\bar{V}$ attracts no more workers than one that offers $V=\bar{V}$ and pays a strictly higher wage. This implies that a solution to the conditions of Proposition 1 also guarantees conditions (ME1)-(ME6) are satisfied and so describes a market equilibrium.

Q.E.D.

\subsection{Existence and Characterization}

We now solve the conditions described in Proposition 1 and so fully characterize a market equilibrium. ${ }^{11}$ A critical step is to note that as the firm's control problem is autonomous and as the firm has a zero rate of time preference, the Hamiltonian used to solve the firm's optimal contract problem is identically zero (Leonard and Long (1992, p. 298)). It follows from (29) in the Appendix that

$$
\begin{aligned}
0= & {[p-w]-\Pi[\delta+\lambda(1-F(V))] } \\
& -\left[1 / u^{\prime}(w)\right]\left[\delta V-u(w)-\lambda \int_{V}^{\bar{V}}[x-V] d F(x)\right] .
\end{aligned}
$$

Using (8) and (9) from Theorem 1, the above implies

$$
\frac{d V_{s}}{d t}=-u^{\prime}\left(w_{s}(t)\right) \frac{d \Pi_{s}}{d t}
$$

along the baseline salary scale. Note, this is an efficiency condition that states that as the worker's wage increases with tenure, the increase in the worker's expected lifetime utility equals the loss in the firm's continuation profit (measured in current worker utils). This much simplifies the analysis as it replaces (13) in Claim 3, which also describes $d V_{s} / d t$ along the baseline salary scale.

The proof of Theorem 2 below identifies closed form solutions to the conditions of Proposition 1. It does this indirectly by first solving for the equilibrium functions in terms of the wages offered by firms. In particular, define $F_{w}\left(w_{0}\right)$ as the proportion of firms whose starting wage is no greater than $w_{0}$, and note that a market equilibrium implies $F_{w}\left(w_{s}(t)\right)=F_{s}(t)$. Similarly, define $1-G_{w}(w)$ as the number of employed workers with current wage no lower than $w$, and so $G_{w}\left(w_{s}(t)\right)=G_{s}(t)$. Finally, define $\Pi_{w}(w)$ where $\Pi_{w}\left(w_{s}(t)\right)=\Pi_{s}(t)$. Of course, $F_{w}, G_{w}$ also have significant empirical interest.

\footnotetext{
${ }^{11}$ We are grateful to an anonymous referee for pointing out the following line of argument.
} 
THEOREM 2: There exists a unique market equilibrium. At this equilibrium, the baseline salary scale $w_{s}$ satisfies

$$
\frac{d w}{d t}=\frac{\delta}{\sqrt{p-\bar{w}}} \frac{p-w}{u^{\prime}(w)} \int_{w}^{\bar{w}} \frac{u^{\prime}(x) d x}{\sqrt{p-x}}
$$

subject to $w=\underline{w}$ at $t=0$. Further,

$$
\begin{aligned}
G_{w} & =\sqrt{\frac{p-\bar{w}}{p-w}}, \\
\Pi_{w} & =\frac{1}{\delta} \sqrt{(p-w)(p-\bar{w})},
\end{aligned}
$$

and for $w>\underline{w}, F_{w}$ is continuous, strictly increasing, and is given by

$$
1-F_{w}=\frac{\delta}{\lambda}\left[\sqrt{\frac{p-w}{p-\bar{w}}}-1-\frac{1}{2 u^{\prime}(w)} \int_{w}^{\bar{w}} \frac{u^{\prime}(x) d x}{\sqrt{(p-\bar{w})(p-x)}}\right],
$$

and has a mass point at $\underline{w}$ where

$$
F_{w}(\underline{w})=\frac{\lambda+\delta}{\lambda(p-\underline{w})} \frac{u(b)-u(\underline{w})}{u(\underline{w})} .
$$

The support of wages paid $[\underline{w}, \bar{w}]$ is nondegenerate and implies $\underline{w}<b, \bar{w}<p$ satisfying

$$
\begin{aligned}
& {\left[\frac{\delta}{\lambda+\delta}\right]^{2}=\frac{p-\bar{w}}{p-\underline{w}},} \\
& u(\underline{w})=u(b)-\frac{\sqrt{p-\underline{w}}}{2} \int_{\underline{w}}^{\bar{w}} \frac{u^{\prime}(x) d x}{\sqrt{p-x}} .
\end{aligned}
$$

PROOF: The proof solves explicitly the conditions of Proposition 1 . We do this in four steps, where the first step is to solve for the equilibrium functions $F_{w}, G_{w}, \Pi_{w}$.

Step 1. To solve for $G_{w}, \Pi_{w}$ note that the constant profit condition (16) implies

$$
\frac{d G_{s}}{d t} \Pi_{s}+\frac{d \Pi_{s}}{d t} G_{s}=0
$$

Substituting out $d G_{s} / d t$ and $d \Pi_{s} / d t$ using (15) and (14) implies $\Pi_{s}=G_{s}(p-$ $\left.w_{s}\right) / \delta$. This condition and the constant profit condition (16) now imply (19) and (20). 
We next solve for $F_{w}$. As $F_{w}\left(w_{s}(t)\right)=F_{s}(t)$ by definition, then

$$
f_{w}\left(w_{s}(t)\right)=\frac{d F_{s} / d t}{d w_{s} / d t}
$$

where $F_{w}^{\prime}(w)=f_{w}(w)$. Using (12) to substitute out $d w_{s} / d t$, and using (17) yields

$$
f_{w}\left(w_{s}\right)=\left[\frac{u^{\prime \prime}\left(w_{s}\right)}{u^{\prime}\left(w_{s}\right)}\right] \frac{d \Pi_{s} / d t}{\lambda \Pi_{s}} .
$$

Substituting out $d \Pi_{s} / d t$ using (14), and using (20) implies

$$
-\frac{u^{\prime}\left(w_{s}\right)}{u^{\prime \prime}\left(w_{s}\right)} f_{w}\left(w_{s}\right)+1-F_{w}\left(w_{s}\right)+\frac{\delta}{\lambda}=\frac{\delta}{\lambda}\left[\frac{p-w_{s}}{p-\bar{w}}\right]^{1 / 2},
$$

which is a first order differential equation for $F_{w}$ with $w=w_{s}$. Multiplying throughout by $u^{\prime \prime}(w)$, and integrating yields

$$
\left[u^{\prime}(w)\left[1-F_{w}(w)\right]+\frac{\delta}{\lambda} u^{\prime}(w)\right]_{w_{0}}^{\bar{w}}=\frac{\delta}{\lambda} \int_{w_{0}}^{\bar{w}} u^{\prime \prime}(x)\left(\frac{p-x}{p-\bar{w}}\right)^{1 / 2} d x .
$$

Integrating the right-hand side by parts and simplifying yields (21).

Step 2. We now solve Proposition 1(a) for $\left\{w_{s}, F_{s}, G_{s}, \Pi_{s}, V_{s}\right\}$. First, $w_{s}$ is characterized. As $(20)$ implies $\Pi_{s}(t)=(1 / \delta)\left[(p-\bar{w})\left(p-w_{s}(t)\right)\right]^{1 / 2}$, differentiation yields

$$
\frac{d \Pi_{s}}{d t}=-\frac{1}{2 \delta}\left[\frac{p-\bar{w}}{p-w_{s}}\right]^{1 / 2} \frac{d w_{s}}{d t}
$$

Substituting out $d \Pi_{s} / d t$ using (14), the solution for $\Pi_{s}$ now implies (18) with $w=w_{s}$. Further for $w \in[\underline{w}, \bar{w}]$ with $\underline{w}>0$ and $\bar{w}<p$, the Fundamental Theorem of Differential Equations implies a solution to (18) exists for all $w \in[\underline{w}, \bar{w}]$, and so $(18)$ with initial value $w_{s}(0)=\underline{w}$ implies $w_{s}$ exists, is strictly increasing, and asymptotes to $\bar{w}$.

Given the above solutions for $F_{w}, G_{w}, \Pi_{w}$ and the baseline salary scale $w_{s}$, the definitions of $F_{w}, G_{w}, \Pi_{w}$ now imply solutions for $F_{s}, G_{s}, \Pi_{s}$. Although not specified in the Theorem, note that $d V_{s} / d t$ is determined by (17) with $d \Pi_{s} / d t$ and $w_{s}$ given above. $V_{s}$ is then the solution to that linear first order differential equation, subject to the boundary condition $\lim _{t \rightarrow \infty} V_{s}(t)=[p-\bar{w}] / \delta$. Note, $t=0$ and $w_{s}=\underline{w}$ implies

$$
\frac{d V_{s}(0)}{d t}=\frac{1}{2} \sqrt{p-\underline{w}} \int_{\underline{w}}^{\bar{w}} \frac{u^{\prime}(x)}{\sqrt{p-x}} d x .
$$


As (18) implies $w_{s} \rightarrow \bar{w}$ as $t \rightarrow \infty$, the above solutions imply

$$
\lim _{t \rightarrow \infty}\left(w_{s}(t), V_{s}(t), \Pi_{s}(t), G_{s}(t), F_{s}(t)\right)=(\bar{w}, \bar{V}, \bar{\Pi}, 1,1) .
$$

Hence, for arbitrary values of $\underline{w}>0$ and $\bar{w}<p$ we have constructed functions $\left\{w_{s}, F_{s}, G_{s}, \Pi_{s}, V_{s}\right\}$ that satisfy Proposition 1a.

Step 3. Here, we solve Proposition 1(b) and 1(c). As $G_{s}(0)=G_{w}(\underline{w})$, then Proposition 1(b) is satisfied if and only if $G_{w}(\underline{w})=\delta /(\lambda+\delta)$. As $G_{w}$ is given by (19), Proposition 1(b) is satisfied if and only if (22) holds.

Proposition 1(c) is satisfied if and only if

$$
\delta V_{s}(0)=u(b)+\lambda \int_{0}^{\infty}\left[V_{s}(t)-V_{u}\right] d F_{s}(t)
$$

and $V_{u}=V_{s}(0)$. Now $V_{s}(0)$ is given by (13) with $t=0$. Given $d V_{s}(0) / d t$ described above, Proposition 1(c) is satisfied if and only if (23) is satisfied and $V_{u}=V_{s}(0)$.

Step 4 . We now prove existence and uniqueness of equilibrium. Note, as long as $\underline{w}>0$ and $\bar{w}<p$, the implied wage offer density

$$
f_{w}=\frac{\delta}{\lambda}\left[\frac{-u^{\prime \prime}(w)}{u^{\prime}(w)^{2}}\right] \int_{w}^{\bar{w}} \frac{u^{\prime}(x) d x}{\sqrt{(p-\bar{w})(p-x)}}
$$

is continuous and strictly positive over $[\underline{w}, \bar{w})$. Also note that $F_{w}(\underline{w}) \geq 0$ if and only if $\underline{w} \leq b$. It now follows that as long as $\underline{w} \in(0, b]$ and $\bar{w}<p$, then the implied $F_{s}, G_{s}$ have the properties of distribution functions (i.e., they are (strictly) increasing over their supports and take values in the interval [0,1]), and that $F(V)$ has properties A2 (i.e., it has connected support and is differentiable over the interior of its support).

Hence, establishing existence and uniqueness of a solution to the conditions of Proposition 1, and therefore a market equilibrium, reduces to finding a pair $(\underline{w}, \bar{w})$ satisfying (22) and (23) with $\underline{w} \in(0, b]$ and $\bar{w} \in[\underline{w}, p)$. Note, (22) describes a straight line and is labelled $X Y$ in Figure 1. It is simple to show $X Y$ has a positive slope that is strictly less than one and passes through the point $(p, p)$. (23) is labelled $R V$ in Figure 1. Concavity of $u$ implies that $R V$ is downward sloping for all $\underline{w} \in(0, b]$. Note, $R V$ passes through $(b, b)$.

We complete the proof of Theorem 2 by showing that $R V$ passes through a point $\left(w_{L}, p\right)$ where $w_{L} \in(0, b)$ as drawn in Figure 1 . To do this, define $\phi(w)$ where

$$
\begin{aligned}
\phi(w)= & u(p)-u(w)-\frac{1}{2}(p-w)^{1 / 2} \int_{w}^{p} \frac{u(p)-u(x)}{(p-x)^{3 / 2}} d x \\
& -2[u(p)-u(b)] .
\end{aligned}
$$




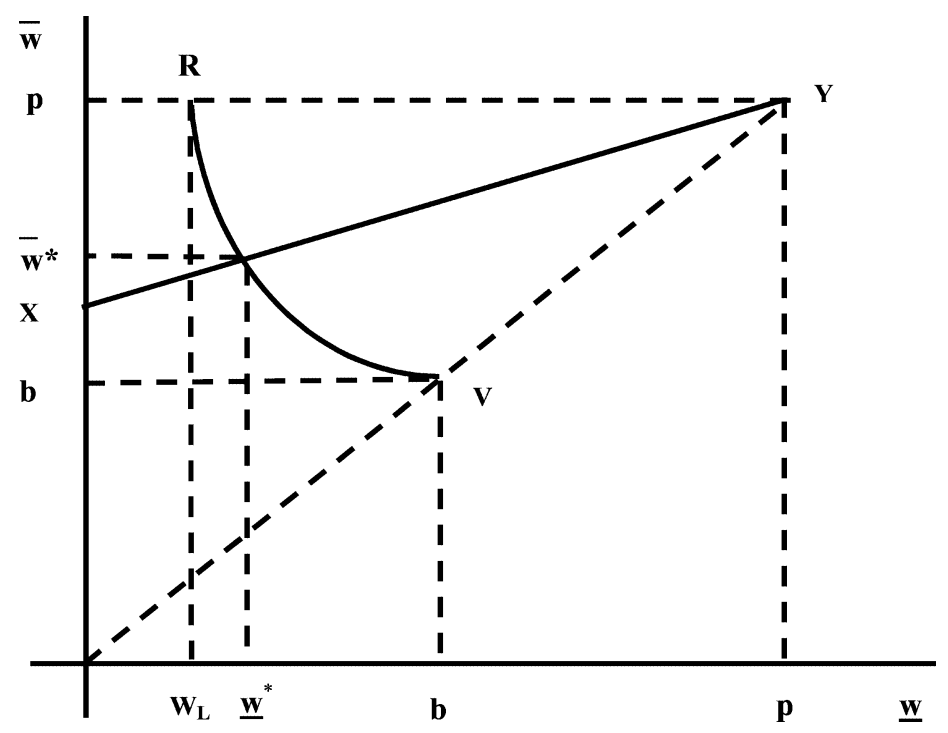

FIGURE 1.

Putting $\bar{w}=p$ and integrating (23) by parts implies $\underline{w}=w_{L}$ where $\phi\left(w_{L}\right)=0$. Inspection establishes that $\phi$ is finite for all $w>0$, is strictly decreasing and is strictly negative at $w=b$. As concavity implies $u(p)-u(x) \leq(p-x) u^{\prime}(x)$, we also have

$$
\begin{aligned}
\phi(w) \geq & u(p)-u(w)-\frac{1}{2}(p-w)^{1 / 2} \int_{w}^{p} \frac{u^{\prime}(x)}{(p-x)^{1 / 2}} d x \\
& -2[u(p)-u(b)] \\
= & \int_{w}^{p} u^{\prime}(x)\left[1-\frac{1}{2}\left(\frac{p-w}{p-x}\right)^{1 / 2}\right] d x-2[u(p)-u(b)] .
\end{aligned}
$$

But $1-(p-w)^{1 / 2} /\left(2(p-x)^{1 / 2}\right)=1 / 2$ at $x=w$ and is strictly positive in a neighborhood of $x=w$. Hence, A1 implies $\phi(w) \rightarrow+\infty$ as $w \rightarrow 0^{+}$and so a $w_{L}>0$ exists satisfying $\phi\left(w_{L}\right)=0$.

As A1 implies $w_{L}>0$ exists, $R V$ is as depicted in Figure 1 . Hence, there exists a unique $(\underline{w}, \bar{w})$ satisfying (22) and (23) and also $\underline{w} \in(0, b]$ and $\bar{w} \in$ $[b, p)$.

Before discussing these results in detail, we quickly consider comparative statics. Suppose there is an increase in $b$. This does not affect the $X Y$ locus, but shifts up the $R V$ locus. The $R V$ locus corresponds to (23) and reflects the reservation value $V_{u}$ of an unemployed worker, given that the distribution of job offers is consistent with wage competition by firms. An increase in $b$ implies 
that the equilibrium $\bar{w}$ and $\underline{w}$ increase. The distribution of wages paid, denoted by $K$, is given by

$$
K(w)=\frac{\lambda+\delta}{\lambda}\left[G_{w}(w)-\frac{\delta}{\lambda+\delta}\right]=\frac{\delta}{\lambda}\left[\sqrt{\frac{p-\underline{w}}{p-w}}-1\right] .
$$

As a higher $\underline{w}$ implies first order stochastic dominance in the distribution of wages paid, an increase in $b$ leads unambiguously to higher wages paid.

Suppose now there is a decrease in search frictions; i.e., $\lambda$ increases. The $R V$ locus does not move, while $X Y$ rotates upwards as it always passes though $(p, p)$. The $X Y$ locus corresponds to (22), and describes equilibrium wage competition between firms. A reduction in search frictions (i.e., an increase in $\lambda$ ), implies $\bar{w}$ increases and $\underline{w}$ decreases. Equation (19) implies that for any wage $w$, the number employed with at least that wage strictly increases as $\lambda$ increases. We do not, however, have first order stochastic dominance in wages paid as there is a fall in unemployment, and the unemployed are willing to accept lower starting wages (i.e., $\underline{w}$ decreases). As $\lambda \rightarrow \infty$ (i.e., frictions disappear), $X Y$ becomes flat and we converge to the competitive outcome where the distribution of wages paid converges to a mass point at $p$; i.e., $K(w) \rightarrow 0$ for all $w<p$ and $\bar{w} \rightarrow p$.

\section{FURTHER DISCUSSION}

\subsection{Alternatives To Assumption A1}

Restriction A1, that $\lim _{w \rightarrow 0^{+}} u(w)=-\infty$, is convenient as it guarantees the corner constraint $w \geq 0$ never binds. It can be shown that assuming $u(0)=0$ and $\lim _{w \rightarrow 0^{+}} u^{\prime}(w)=\infty$ is not sufficient to ensure $w>0$ in an optimal contract (see the proof of Theorem 1). If this alternative assumption is made, the baseline salary scale may have an initial phase where firms pay $w=0$. The analysis above remains valid for the nonbinding phase (which always exists; otherwise job seekers reject a job offer $w=0$ for all tenures) and the wage distributions are as implied by Theorem 2, except possibly with a mass point at $\underline{w}=0$. The same argument also applies if the government imposes a minimum wage policy, that $w \geq w_{\min }$, which may or may not bind in equilibrium.

Suppose that we drop A1 and instead only assume that $u$ is increasing and strictly concave. The above analysis remains valid as long as the corner constraint $w \geq 0$ is never binding in an optimal contract. If $\underline{w}>0$, where $\underline{w}$ is determined as the intersection of $R V$ and $X Y$ as depicted in Figure 1, then the corner constraint $w \geq 0$ never binds in a market equilibrium. Given $u$ is strictly concave, a sufficient restriction that guarantees $\underline{w}>0$, and therefore a market equilibrium exists, is that $b \in\left[w_{1}, p\right)$ where

$$
w_{1}=\left[1-\left(\frac{\delta}{\delta+\lambda}\right)^{2}\right] p
$$




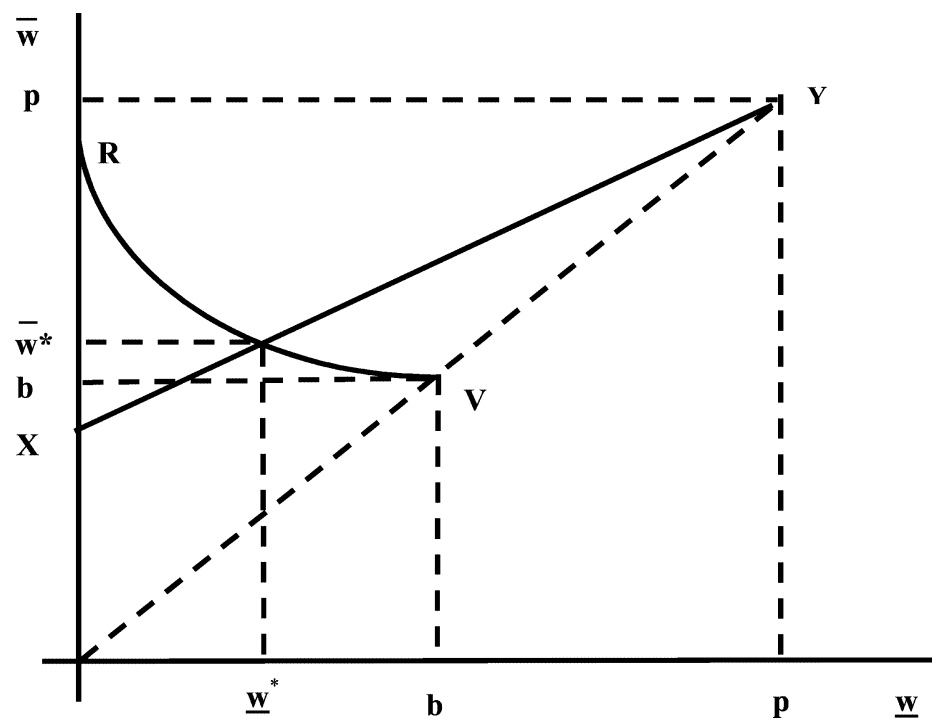

FIGURE 2.

Strict concavity of $u$ implies the $R V$ locus is strictly decreasing and passes though $(b, b) . X Y$ is a straight line with intercept $w_{1}<p$ and passes through $(p, p)$. As shown in Figure 2, if $b>X$, the restriction $b \in\left[w_{1}, p\right)$ guarantees a market equilibrium exists with $\underline{w}>0$.

\subsection{Constant Relative Risk Aversion}

Given $b$ large enough and $u$ is strictly concave, we now consider what happens in equilibrium as worker risk aversion changes. To do this, we restrict attention to CRRA utility functions, $u(x)=x^{1-\sigma} /(1-\sigma)$ with $\sigma>0$.

Setting $p=5$ and $\delta / \lambda=0.1$, then $b=4.6$ is large enough to guarantee $\underline{w}>0$ in what follows. Table I describes the equilibrium $\underline{w}, \bar{w}$ and the mass point $F_{w}(\underline{w})$ for various $\sigma$.

TABLE I

\begin{tabular}{lccc}
\hline \hline$\sigma$ & $\underline{w}$ & $\bar{w}$ & $F_{w}(\underline{w})$ \\
\hline 0.0 & 0.600 & 4.964 & 1.000 \\
0.1 & 1.333 & 4.970 & 0.911 \\
0.2 & 1.751 & 4.973 & 0.864 \\
0.4 & 2.223 & 4.977 & 0.803 \\
0.8 & 2.728 & 4.981 & 0.727 \\
1.4 & 3.126 & 4.985 & 0.657 \\
$\infty$ & 4.600 & 4.997 & 0.000 \\
\hline
\end{tabular}


As $\sigma \rightarrow 0$ (risk neutral workers), the market equilibrium converges to a well defined limit. Even with $\sigma=0$, a solution to the conditions of Theorem 2 exists (with $b$ large enough) and implies a baseline salary scale that is a smooth, strictly increasing concave function. The solution for $\underline{w}$, however, implies $F_{w}(\underline{w})=1$; the distribution of contract offers is degenerate, even though, by construction, firms are indifferent to offering any contract with starting wage $w_{0} \in[\underline{w}, \bar{w}]$. Such an outcome fails the formal definition of a market equilibrium-the implied distribution of offers $F($.) does not satisfy A2. Nevertheless, given such an $F$, the baseline salary scale satisfies the equations of Theorem 1 and so describes an optimal contract. The equilibrium outcome is that all workers receive the same starting payoff and none ever quit. Indeed, as all firms offer $V_{s}(0)=V_{u}$, workers obtain no surplus through finding employment and so $V_{u}=u(b) / \delta$. Equilibrium implies the pure monopsony outcome where employers extract all match rents (analogous to the Diamond paradox; see Diamond (1971)).

Stevens $(1999,2002)$ was the first paper to establish this degeneracy result. She also shows there is a continuum of payoff equivalent optimal contracts. Theorem 1 confirms this as

$$
\frac{-u^{\prime \prime}(w)}{u^{\prime}(w)^{2}} \frac{d w}{d t}=\lambda F^{\prime}(V) \Pi
$$

describes how wages change optimally with tenure, and $d w / d t$ is ill-determined given $u^{\prime \prime}=0$ (risk neutral workers) and $F^{\prime}(V)=0$ (degenerate offers). When workers are risk neutral, the baseline salary scale implied by Theorem 2 describes only one of many equilibrium wage tenure contracts. The baseline salary scale, however, describes the unique limiting equilibrium contract as $\sigma \rightarrow 0$.

As described above, the equilibrium distribution of wages paid is

$$
K(w ; \sigma)=\frac{\delta}{\lambda}\left[\sqrt{\frac{p-\underline{w}}{p-w}}-1\right]
$$

where $\underline{w}=\underline{w}(\sigma)$. Note, $\sigma$ changes this distribution only through its impact on $\underline{w}$. As shown in Table I, an increase in $\sigma$ leads to an increase $\underline{w}$, and therefore an increase in worker risk aversion leads to first order stochastic dominance in the distribution of wages paid.

To explain this outcome, note that backloading wages using an increasing wage-tenure contract increases the expected lifetime payoff of those employees who have significant tenures. From the other firms' standpoint, attracting such workers requires offering a high starting payoff, which is relatively unprofitable. Stevens (2002) finds that when firms compete in step contracts, firms can backload wages sufficiently that, in equilibrium, poaching employed workers by offering a high starting payoff is strictly dominated by offering a low starting 
payoff to extract full search rents from unemployed job seekers. The underlying insight is that firms use wage/tenure contracts to reduce employee quit incentives, which then affects the incentives of other firms to post high value contracts.

The comparative static on $\sigma$ can be explained as follows. First, note that an increase in worker risk aversion implies that the insurance value of a smoother wage stream is greater, and so firms have less incentive to backload wages. Table I demonstrates that an increase in $\sigma$ leads to a fall in the range of wages paid $[\bar{w}-\underline{w}]$ along the baseline salary scale.

Reduced backloading of worker wages then implies that employees with significant tenures have relatively low expected lifetime payoffs. In contrast to Stevens (2002), firms then have a greater incentive to raise their starting wage and so poach employed workers using on-the-job search. Table I demonstrates that as $\sigma$ increases, the mass point in $F_{w}$ at $\underline{w}$ decreases; more firms offer higher starting wages.

As more firms offer starting wages above $\underline{w}$, the value of continued search by unemployed workers increases, which raises $V_{u}$. This then leads to an increase in $\underline{w}$ and an increase in wages paid as described in Table I.

As $\sigma \rightarrow \infty$, it can be shown analytically that the market equilibrium converges to the equilibrium characterized in $\mathrm{B} / \mathrm{M}$. In this limit, the insurance effect dominates so that wage tenure effects become arbitrarily small and the baseline salary scale becomes flat. Given firms compete in flat wage contracts, equilibrium search and wage competition then implies the B/M outcome where, given that the offer arrival rate $\lambda$ is the same for employed and unemployed workers, equilibrium implies $\underline{w}=b$.

Note that although the functional form describing the distribution of wages paid, $K$, is the same across all equilibria, the composition of worker wage growth, via quit turnover and wage/tenure effects, varies across the equilibria. For example, in the limiting $\mathrm{B} / \mathrm{M}$ case (where $\sigma \rightarrow \infty$ ), all worker wage growth arises through on-the-job search and quit turnover-there are no wage-tenure effects. It should also be noted that this high quit outcome yields the highest wages paid in equilibrium. In contrast, in the limiting Stevens case $(\sigma \rightarrow 0)$, all worker wage growth arises through wage tenure effects-there is no quit turnover. This zero quit outcome yields the pure monopsony outcome.

\subsection{Dropping Assumption A2}

Finally, we reconsider Assumption A2. Theorem 1 establishes that an optimal contract implies

$$
\frac{u^{\prime}\left(w^{*}(0 \mid .)\right)}{u^{\prime}\left(w^{*}(\tau \mid .)\right)}=1+u^{\prime}\left(w^{*}(0 \mid .)\right) \int_{0}^{\tau} \lambda F^{\prime}\left(V^{*}(t \mid .)\right) \Pi^{*}(t \mid .) d t,
$$


i.e., the optimal wage paid at each tenure depends on the density of outside wage offers. If $F$ is not differentiable in the interior of its support, then an optimal wage contract may not exist and a market equilibrium is ill-defined.

It can also be argued that a connected support is a necessary property of equilibrium. In particular, given an arbitrary value for $\bar{w} \in\left[w_{1}, p\right)$ and endpoint

$$
\left(w_{s}, V_{s}, \Pi_{s}, G_{s}, F_{s}\right)=(\bar{w}, \bar{V}, \bar{\Pi}, 1,1),
$$

a backward induction argument along the saddle path implied by Proposition 1(a) establishes that $F^{\prime}\left(V_{s}\right)>0$ while $w_{s}>0$. The intuition is that if there were a hole, say over $\left[V^{-}, V^{+}\right]$, then offering a starting payoff $V_{0}$ equal to $V^{-}$ plus a cent would strictly dominate offering $V^{+}$(i.e., a hole in $F$ is inconsistent with equal (steady state flow) profit).

\section{CONCLUSION}

In this study a reasonably standard labor market with frictions has been considered: workers and firms are homogeneous, there is no capital market, firms make take it or leave it offers, and workers also search while employed. Within such an environment we have shown that when workers are risk averse, the equilibrium can be characterized by two major features. First, each firm offers a wage-tenure contract that implies any employee's wage smoothly increases with tenure. Second, there is a nondegenerate distribution of initial wage offers made by the firms in the market with a positive mass offering the lowest initial wage. In such an equilibrium there is worker turnover as an employed worker may contact a firm making a more desirable offer than his or her current employer. This implies that firms offering more generous offers have a greater steady state number of employees and suffer fewer quits than firms offering less generous offers. Further, in equilibrium any worker's increase in wage through time will be due to both wage-tenure effects and job-turnover effects. As we can explicitly solve for the baseline salary scale and know the quit rate of the worker from the firm, it is possible to calculate the expected proportion of a worker's wage growth through time due to wage-tenure effects as a function of the parameters of the model. Indeed, as we can explicitly solve for the equilibrium characteristics of the model, empirical investigation may not be that difficult.

Several extensions of the basic framework should yield new important avenues of research. The most important of these is to extend the framework to allow for heterogeneous firms and workers. Although such extensions may not be easy to achieve, the results should be of great interest to empirical researchers. If it is assumed that firms are heterogeneous in an otherwise identical model to that used above, the baseline salary scale property of equilibrium is lost. This much complicates the analysis. If, for example, there are two types 
of firms, it is reasonable to conjecture that in equilibrium there will be two baseline salary scales. It is the relationship between these two salary scales that will determine the nature of equilibrium. An equilibrium analysis when firms are homogenous but workers are heterogenous, although not trivial to achieve, should also lead to new insights.

Dept. of Economics, University of Essex, Wivenhoe Park, Colchester, CO4 3SQ, U.K., and Dept. of Economics, University of Pennsylvania, 3718 Locust Walk, Philadelphia, PA 19104, U.S.; kennethb@econ.upenn.edu

\section{and}

Dept. of Economics, University of Essex, Wivenhoe Park, Colchester, CO4 3SQ, U.K., and Institut d'Analisi Economica (CSIC), Barcelona, Spain; mcole@essex. ac.uk.

Manuscript received October, 2001; final revision received September, 2002.

\section{APPENDIX}

Proof OF THEOREM 1: Fix an $F$ satisfying A1 and a $V_{u} \leq \underline{V}$. Choose any $V_{0} \in[\underline{V}, \bar{V})$. We first establish some preliminary results implied by optimality (Claim S1). Step 1 then uses optimal control theory to characterize how wages change optimally with tenure. Step 2 then identifies the appropriate transversality condition. Let $\Pi(t \mid w()$.$) denote the firm's expected profit given a$ worker with tenure $t$ and wage contract $w($.$) .$

CLAIM S1: Given $V_{0} \in[\underline{V}, \bar{V})$ optimality implies:

(a) $V_{u} \leq V\left(\tau \mid w^{*}\right) \leq \bar{V}$ for all $\tau \geq 0$, and so $V$ satisfies the Bellman equation (1) subject to the boundary condition that $V$ is uniformly bounded.

(b) $0<\Pi\left(t \mid w^{*}\right) \leq p / \delta$ for all $t$.

PROOF: Contradiction arguments are used to establish the claims.

(a) Suppose a $\tau \geq 0$ exists where $V\left(\tau \mid w^{*}\right)<V_{u}$. In this case the worker quits and obtains payoff $V_{u}$ while the firm obtains a zero payoff. Consider instead wage payments $w(t)=b$ for all $t \geq \tau$. In that case the worker's continuation payoff at $\tau$ is still $V_{u}$ but the worker does not quit into unemployment, while $b<p$ implies the firm makes strictly positive profit, which contradicts the optimality of the original wage contract. Hence, $V\left(\tau \mid w^{*}\right) \geq V_{u}$ for all $\tau$.

Now suppose a $\tau \geq 0$ exists where $V\left(\tau \mid w^{*}\right)>\bar{V}$. As $V\left(0 \mid w^{*}\right)=V_{0}<\bar{V}$ and $V$ is continuous over $t$ (it is differentiable), there exists tenure $\tau^{\prime}>0$ where $V\left(\tau^{\prime} \mid w^{*}\right)=\bar{V}$. Claim 1 , however, implies the optimal contract specifies $w=\bar{w}$ for all $\tau \geq \tau^{\prime}$ and therefore $V=\bar{V}$ for all $\tau \geq \tau^{\prime}$, which is the required contradiction.

(b) Suppose a $\tau \geq 0$ exists where $\Pi\left(\tau \mid w^{*}\right) \leq 0$. Part (a) implies $V\left(\tau \mid w^{*}\right) \in\left[V_{u}, \bar{V}\right]$. Consider the alternative contract $\widehat{w}_{T}$ that for tenures $t \geq \tau$ specifies $w(t)=b$ for $t \leq \tau+T$, and $w(t)=\bar{w}$ for $t>\tau+T$, for some $T \geq 0$. Note, this describes a step contract where after additional tenure $T$, the firm raises the worker's wage from $b$ to $\bar{w}$. If $T=0$, Claim 1 implies this contract implies continuation payoff $V\left(\tau \mid \widehat{w}_{T}\right)=\bar{V}$, while if $T=\infty$ it offers continuation payoff $V\left(\tau \mid \widehat{w}_{T}\right)=V_{u}$. As this continuation payoff is continuous and strictly decreasing in $T$, a $T^{\prime} \geq 0$ exists so that this contract offers continuation payoff $V\left(\tau \mid \widehat{w}_{T^{\prime}}\right)=V\left(\tau \mid w^{*}\right) \in\left[V_{u}, \bar{V}\right]$. As $\bar{w}<p$, this contract makes strictly positive profit, which contradicts the optimality of $w^{*}$. As $w \geq 0$ by assumption, and a worker leaves at a rate no lower than $\delta, \Pi \leq p / \delta$ is immediate.

Q.E.D. 
Step 1. Optimal control theory. Claim S1 establishes that the firm's optimal wage contract $w^{*}$ solves the programming problem

$$
\max _{w \geq 0} \int_{0}^{\infty} \psi(t)[p-w(t)] d t
$$

where

$$
\begin{aligned}
& \dot{\psi}=-[\delta+\lambda(1-F(V))] \psi, \\
& \dot{V}=\delta V-u(w)-\lambda \int_{V}^{\bar{V}}[x-V] d F(x),
\end{aligned}
$$

with starting values

$$
\psi(0)=1, \quad V(0)=V_{0},
$$

and $V$ is uniformly bounded, satisfying

$$
V_{u} \leq V(t) \leq \bar{V} \text { for all } t .
$$

The following maximizes (24) but only subject to (25)-(27); i.e., it ignores the constraint (28). It shall be shown that (28) is automatically satisfied at the optimum and so is never a binding constraint.

Define the Hamiltonian

$$
H=\psi[p-w]-x_{\psi}[\delta+\lambda(1-F(V))] \psi+x_{V}\left[\delta V-u(w)-\lambda \int_{V}^{\bar{V}}[x-V] d F(x)\right],
$$

where $x_{\psi}$ and $x_{V}$ denote the costate variables associated with the state variables $\psi$ and $V$. Then the Maximum Principle implies the necessary conditions for a maximum at any tenure $t$ are:

$$
\begin{array}{rlll}
\text { either } & w=0 \text { and } \quad \partial H / \partial w \leq 0 \Leftrightarrow x_{V} / \psi \geq 0 \\
\text { or } \quad w>0 & \text { and } \quad \psi+x_{V} u^{\prime}(w)=0 \Leftrightarrow x_{V} / \psi<0 \quad \text { and } \quad 1 / u^{\prime}(w)=-x_{V} / \psi,
\end{array}
$$

where

$$
\begin{aligned}
& \dot{x}_{V}=-x_{V}[\delta+\lambda(1-F(V))]-x_{\psi} \lambda F^{\prime}(V) \psi, \\
& \dot{x}_{\psi}=-[p-w]+x_{\psi}[\delta+\lambda(1-F(V))],
\end{aligned}
$$

and $\psi, V$ satisfy the differential equations and initial values described above. Note this is an autonomous problem and as there is no discounting, $H=0$ at the optimum (Leonard and Long (1992, p. 298)).

As (32) is linear in $x_{\psi}$, using $\psi$ as the integrating factor yields

$$
x_{\psi}(t) \psi(t)=\int_{t}^{\infty} \psi(s)[p-w(s)] d s+A_{2}
$$

where $A_{2}$ is the constant of integration. As the firm's continuation payoff is given by

$$
\Pi(t \mid w)=\int_{t}^{\infty} \frac{\psi(s)}{\psi(t)}[p-w(s)] d s,
$$

we obtain $x_{\psi}(t)=\Pi(t \mid)+.A_{2} / \psi(t)$. 
A1 and $V \geq V_{u}>-\infty$ require $w>0$ almost everywhere. Hence, (30) implies $x_{V} / \psi<0$ almost everywhere where $1 / u^{\prime}(w)=-x_{V} / \psi$. Substituting out $x_{V}$ and $x_{\psi}$ in the definition of the Hamiltonian, (29), and noting $H=0$ at the optimum, implies

$$
\begin{aligned}
0= & {[p-w]-\left[\Pi+A_{2} / \psi\right][\delta+\lambda(1-F(V))] } \\
& -\left[1 / u^{\prime}(w)\right]\left[\delta V-u(w)-\lambda \int_{V}^{\bar{V}}[x-V] d F(x)\right]
\end{aligned}
$$

almost everywhere. As $\delta>0$ implies $\psi \rightarrow 0$ as $t \rightarrow \infty, A_{2} \neq 0$ implies the second term becomes unboundedly large in absolute value. As Claim S1 implies $V, \Pi$ are uniformly bounded, then $A_{2} \neq 0$ implies $w>0$ becomes unboundedly large almost everywhere as $t \rightarrow \infty$ and so $\Pi<0$ for $t$ large enough. Therefore $A_{2} \neq 0$ contradicts $\Pi>0$ for all $t$. Note that $A_{2}=0$ implies $x_{\psi} \equiv \Pi$ and (32) implies the differential equation for $\Pi,(9)$, as stated in the Theorem.

As (31) is linear in $x_{V}$, using $1 / \psi$ as the integrating factor yields

$$
\frac{x_{V}(t)}{\psi(t)}=-\int_{0}^{t} \lambda F^{\prime}(V(s)) \Pi(s) d s+A_{1}
$$

where $A_{1}$ is the constant of integration. Note, $\Pi>0$ implies $x_{V} / \psi$ is decreasing over time. For those $t$ where $x_{V} / \psi<0,(30)$ implies $w>0$ and satisfies

$$
\frac{1}{u^{\prime}(w(t))}=\int_{0}^{t} \lambda F^{\prime}(V(s)) \Pi(s) d s-A_{1} .
$$

Differentiating with respect to $t$ implies

$$
\frac{-u^{\prime \prime}(w)}{u^{\prime}(w)^{2}} \frac{d w}{d t}=\lambda F^{\prime}(V) \Pi
$$

for such $t$. If $A_{1}>0$, then $x_{V} / \psi \geq 0$ for $t$ small enough and (30) then implies $w=0$; i.e., the corner constraint can bind for small enough $t$. But as $w>0$ almost everywhere, the corner constraint can only bind at $t=0$. Hence, $w$ evolves according to (33) for all $t>0$, and so $w, V, \Pi$ evolve according to the differential equation system as described in the Theorem.

Step 2. The Transversality Condition. Claim S1 implies $\Pi$ is strictly positive and so (33) implies $w$ is increasing in tenure. Hence, $V$ is also increasing in tenure. As $V$ is bounded, monotonicity implies $V$ must converge to some limit value $V^{\infty}$. Further, as $V(0)=V_{0} \in[\underline{V}, \bar{V}),(33)$ and $V \leq \bar{V}$ imply $V^{\infty}=\bar{V}$. Further, (8) implies $w$ must converge to $\bar{w}$ and (9) implies $\lim _{t \rightarrow \infty} \Pi(t)=\bar{\Pi}$.

Finally, note that $V$ increasing implies $V \in\left[V_{0}, \bar{V}\right]$ for all $t$, and so this solution also satisfies (28) (and so does not bind).

Q.E.D.

\section{REFERENCES}

Acemoglu, D., AND R. SHIMer (1999): "Wage and Technology Dispersion," Review of Economic Studies, 68, 585-608.

AlbreChT, J., AND B. AXELL (1984): “An Equilibrium Model of Search Unemployment,” Journal of Political Economy, 92, 824-840.

BONTEMPS, C., J.-M. ROBIN, AND G. J. VAN DEN BERG (1999): "An Empirical Equilibrium Job Search Model with Search on the Job and Heterogenous Workers," International Economic Review, 40, 1039-1075. (2000): "Equilibrium Search with Continuous Productivity Dispersion: Theory and NonParametric Estimation," International Economic Review, 41, 305-358.

BuRdETT, K., AND D. T. MORTENSEN (1989): "Equilibrium Wage Distributions: Compensating and Otherwise," MEDS Working Paper, Northwestern University. 
(1998): "Wage Differentials, Employer Size, and Unemployment," International Economic Review, 39, 257-273.

DiAmOND, P. A. (1971): “A Model of Price Adjustment," Journal of Economic Theory, 3, 156-168. ECKSTEIN, Z., AND K. I. WOLPIN (1990): "Estimating a Market Equilibrium Search Model from Panel Data on Individuals," Econometrica, 58, 783-808.

LeOnARD, D., AND N. V. LONG (1992): Optimal Control Theory and Static Optimization in Economics. Cambridge: Cambridge University Press.

Mortensen, D. T. (2002): "Wage Dispersion: Why are Similar Workers Paid Differently," Mimeo, Northwestern University.

Postel-VinAY, F., AND J.-M. RoBIN (2002a): "The Distribution of Earnings in an Equilibrium Search Model with State-Dependent Offers and Counter-Offers," International Economic Review, 41, 989-1017.

(2002b): "Equilibrium Wage Dispersion with Worker and Employer Heterogeneity," Econometrica, 70, 2295-2350.

SHIMER, R. (1996): "Contracts in a Frictional Labor Market," Mimeo, MIT.

STEVENS, M. (1999): "Wage-Tenure Contraction in a Frictional Labour Market: Firms' Strategies for Recruitment and Retention," Mimeo, Oxford University. (2002): "Wage-Tenure Contraction in a Frictional Labour Market: Firms' Strategies for Recruitment and Retention," Mimeo, Oxford University.

VAN DEN BERG, G. J. (1999): "Empirical Inference with Equilibrium Search Models of the Labor Market," Economic Journal, 109, F283-F307.

VAN DEN BERG, G. J., AND G. RIDDER (1998): "An Empirical Equilibrium Search Model of the Labor Market,” Econometrica, 66, 1183-1221. 